\title{
Evaluation of Critical Thinking in Higher Education in Oman
}

\author{
Renjith Kumar.R ${ }^{1} \&$ Rajani James ${ }^{1}$ \\ ${ }^{1}$ Department of Business Studies, Nizwa College of Technology, Sultanate of Oman \\ Correspondence: Renjith Kumar.R, Department of Business Studies, Nizwa College of Technology, Sultanate of \\ Oman, Tel: 96-89-570-1571. E-mail: cvrrkachu@gmail.com
}

Received: March 27, 2015

Accepted: April 21, 2015

Online Published: May 27, 2015

doi:10.5430/ijhe.v4n3p33

URL: http://dx.doi.org/10.5430/ijhe.v4n3p33

\begin{abstract}
The study aims to identify the critical level thinking of students in higher education. It is focused to evaluate the level of critical thinking variables among the students in Nizwa College of Technology and to determine whether these variables are influenced by gender and department. The data for the research is collected from 281 diploma students from Engineering, Information Technology and Business departments of Nizwa College of Technology, Sultanate of Oman. The statements for the instrument are adopted from Watson-Glaser Critical Thinking model consisting of the five variables, namely Inference, Assumptions, Deduction, Interpretation and Arguments. Male students show more of inference and interpretation skills than female students. It is proved that gender has no relationship on assumption and deduction. Females show more argument skills than male students. Students in Engineering department have a high inference level and deduction level than other departments. Business and Information Technology department students have high assumption level than Engineering students. Business department students have high evaluation of arguments than other departments. Students of Information Technology department are high in interpretation than other students.
\end{abstract}

Key words: Inference, Assumptions, Deduction, Interpretation, Arguments

\section{Introduction}

Educators have long been aware of the importance of critical thinking skills as an outcome of student learning. Critical thinking skills are necessary to prepare students for the post-secondary education and work place. Critical thinking as a cross-disciplinary skill is vital for college and employment. Critical thinking is a rational and reflective mental act on the issues, arguments and careful thought on the basis of knowledge, ideas and experiences in order to reach a reasonable conclusion. A critical thinking is an advanced level of exercising a mental activity based on rational principles. It is a critical tool in learning and leading a valuable life (Saner eta al, 2012). Critical thinking is reasonable, reflective thinking that is aimed at deciding what to believe or what to do (Ennis, 2011). In recent years critical thinking has become a central focus of education. If critical thinking is really as vital as its proponents maintain, then it will also be important in applied fields such as teacher education (Hager \& Kaye, 1992). The researchers through this study intent to explore the implications critical thinking of students by adopting Watson-Glaser Critical Thinking model. According to Ennis (1993), the purposes of critical thinking assessment includes; (1) diagnosing the level of students critical thinking (2) giving students feedback about their critical thinking prowess. (3) motivating students to be better at critical thinking (4) informing teachers about the success of their efforts to teach students to think critically (5) doing research about critical thinking instructional questions and issues (6) providing help in deciding whether a student should enter an educational program.

\subsection{Scope of the study}

Halpern (1998) points to research from the field of psychology concluded many adults fail to think critically in many situations. Kennedy et al., (1991) and Van Gelder (2005) have concluded that many adults lack basic reasoning skills. Halpern (1998) cites the example that large numbers of people profess to believe in paranormal phenomena, despite a lack of evidence in support of such things. Halpern attributes such failures to reasoning. One reason for this gap in basic reasoning skills may be deficient educational experiences. Paul (1992) argues that typical school instruction does not encourage the development of higher-order thinking skills like critical thinking. Kennedy et al. (1991) point out that empirical research suggests that students of all intellectual ability levels can benefit from critical thinking instruction. Similarly, Lewis and Smith (1993) argue that critical thinking skills are for everyone, not just the gifted. Thus critical thinking lament the poor state of critical thinking in most educated adults and children. No empirical 
studies has been conducted on critical thinking in Nizwa College of Technology and therefore the output of this research identifies and improves the level of critical thinking ability of students.

\subsection{Research questions}

The following are the research questions addressed in this study;

1. What is the level of critical thinking variables among the students in Nizwa College of Technology?

2. What is the influence of critical thinking variables on gender?

3. What is the impact of critical thinking variables in different departments?

\subsection{Literature review}

Critical thinking is a cognitive activity, associated with using the mind. Learning to think in critically analytical and evaluative ways means using mental processes such as attention, categorization, selection and judgment. However, many people who have the potential to develop more effective critical thinking can be prevented from doing so for a variety of reasons apart from a lack of ability. In particular, personal and emotional or affective reasons can create barriers (Stella, 2011). Bailin (2002) defines critical thinking as thinking of a particular quality-essentially good thinking that meets specified criteria or standards of adequacy and accuracy. Critical thinking is a "disciplined, self-directed thinking that exemplifies the perfections of thinking appropriate to a particular mode or domain of thought" (Paul, 1992). According to Sternberg (1986) it is "the mental processes, strategies, and representations people use to solve problems, make decisions, and learn new concepts". Halpern (1998) identified the components of Critical thinking: understanding how cause is determined, recognizing and criticizing assumptions, analyzing means-goals relationships, giving reasons to support a conclusion, assessing degrees of likelihood and uncertainty, incorporating isolated data into a wider framework, and using analogies to solve problems. Giancarlo and Facione (2001) pointed out that a more comprehensive view of critical thinking must include dispositions, which refers to a person's inclination to use critical thinking skills when faced with problems to solve, ideas to evaluate, or decisions to make. Willingham (2007) indicates that very young children have been observed thinking critically, whereas trained scientists occasionally fall prey to errors in reasoning. Kennedy, et al. (1991) surveyed the research literature and concluded that, although critical thinking ability appears to improve with age, even young children can benefit from critical thinking instruction.

\section{Methodology}

The data for the research is collected from 281 Diploma students of Nizwa College of Technology from Engineering, Information Technology and Business departments. The study period was semester one (September 2014 till December 2014) of academic year 2014-2015. The population of diploma students is 442. A structured questionnaire is used for data collection. The statements for the instrument are adopted from Watson-Glaser Critical Thinking model that includes five parameters, namely Inference, Assumptions, Deduction, Interpretation and Arguments. Situational questions related to these five variables are asked to the respondents. The correct response is given a score of 1 . Thus the cumulative score for each variable is calculated for each respondent. Hypothesis testing is done with the help of Chi square and the level of each attribute is categorized as low, medium and high by using the formula: Average+-S.D. Coefficient of variation is used to find out the consistency and reliability among the critical thinking variables. ANOVA is used to identify the equality of means among the critical thinking variables.

\section{Results and Discussion}

\subsection{Inference}

An inference is a conclusion that a person can draw from certain observed or supposed facts. Each statement of fact is followed by several possible inferences. Conclusions are drawn from the stated facts. The test examines each inference separately, and makes a decision as to its degree of truth or falsity. The mean inference of 281 students is 0.91 and the standard deviation is 0.83 . Out of 281 students surveyed, $38 \%$ have moderate level of inference and the inference level is high for $25 \%$ of the students.

Table 1.1 Inference gender wise

\begin{tabular}{|cccccc|}
\hline Gender & No. of responses & Average & Above average & Below average & Range \\
\hline Males & 145 & 0.97 & $99(68)$ & $46(32)$ & $0-4$ \\
Females & 136 & 0.83 & $78(57)$ & $136(43)$ & $0-3$ \\
Total & 281 & 0.91 & $177(63)$ & $281(37)$ & $0-4$ \\
\hline
\end{tabular}


The mean value of inference for male students is 0.97 and that for female students is 0.83 . The mean inference of male students is more than overall mean $(0.91) .68 \%$ of male students are above mean when compared with the female students $(57 \%) .43 \%$ of the females are below the mean inference.

Table 1.2 Level of Inference Gender wise

\begin{tabular}{|ccccc|}
\hline Gender & Low & Medium & High & Total \\
\hline Males & & & & \\
Females & $46(32)$ & $61(42)$ & $38(26)$ & 145 \\
Total & $58(43)$ & $44(32)$ & $34(25)$ & 136 \\
& $104(37)$ & $105(38)$ & $72(25)$ & 281 \\
\hline
\end{tabular}

Table 1.2 summarizes the differences in the level of inferences between male and female students. It is evident from table 1.2 that $26 \%$ of the male students have high inference level than the overall average $(25 \%)$. The inference level for female students is $25 \%$. Ho: Male students in Nizwa College of Technology have a high level of inference than female students. The observed value of $\chi^{2}(4.07)$ is less than the critical value (5.99) at $5 \%$ confidence level with 2 degrees of freedom. It is thus concluded that male students excel in inference than female students.

Table 1.3 Inference among departments

\begin{tabular}{|lccccc|}
\hline \multicolumn{1}{|c}{ Department } & No. of responses & Mean & Above mean & Below mean & Range \\
\hline Business & 78 & 0.79 & $42(54)$ & $36(46)$ & $0-3$ \\
Engineering & 170 & 0.96 & $113(67)$ & $57(33)$ & $0-4$ \\
Information Technology & 33 & 0.88 & $22(67)$ & $11(33)$ & $0-2$ \\
Total & 281 & 0.91 & $177(63)$ & $104(37)$ & $0-4$ \\
\hline
\end{tabular}

Table 1.3 displays Business and Information Technology departments' inference mean are 0.79 and 0.88 respectively which is less than the overall inference mean (0.91). The mean inference of Engineering department students is 0.96 which is higher than the inference mean (0.91). $67 \%$ of the students in Engineering and Information Technology are above the overall mean in inference. $46 \%$ of the business students are below the average.

Table1.4 Department and level of Inference

\begin{tabular}{|lcccc|}
\hline & Low & Medium & High & Total \\
Department & & & & \\
\hline Business & $36(47)$ & $23(29)$ & $19(24)$ & 78 \\
Engineering & $57(34)$ & $67(39)$ & $46(27)$ & 170 \\
Information Technology & $11(34)$ & $15(45)$ & $7(21)$ & 33 \\
Total & $104(37)$ & $105(38)$ & $72(25)$ & 281 \\
\hline
\end{tabular}

Table 1.4 exhibits that from an overall percentage (25\%), Engineering students are high in inference $(27 \%)$. The inference level for $45 \%$ students in the Information Technology department is medium whereas $47 \%$ of the students from Business department have low inference level. Ho: Engineering department students have a high inference level than other students. The observed value of $\chi^{2}(4.93)$ is less than the table value (9.49) at 5\% confidence level with 4 degrees of freedom. It is thus concluded that students in Engineering department have a high inference level than other departments.

\subsection{Recognition of Assumptions}

An assumption is something presupposed or taken for granted. Each statement is followed by several proposed assumptions. The student decides whether these assumptions can be taken for granted, justifiable or unjustifiable. The mean value of assumption is 2.81. The standard deviation calculated is 0.86 . 
Table 2.1 Gender and Assumption

\begin{tabular}{|cccccc|}
\hline Gender & No. of responses & Average & Above average & Below average & Range \\
\hline Males & 145 & 2.6 & $85(59)$ & $60(41)$ & $0-4$ \\
Females & 136 & 3.03 & $38(30)$ & $98(70)$ & $1-4$ \\
Total & 281 & 2.81 & $191(68)$ & $90(32)$ & $0-4$ \\
\hline
\end{tabular}

The mean assumption for male students is 2.6 and that of female students is 3.03 which is more than the total mean (2.81). $59 \%$ of the male students have an above mean level of assumption.

Table 2.2 Gender and level of Assumption

\begin{tabular}{|ccccc|}
\hline Assumptions & Low & Medium & High & Total \\
\hline Males & $17(12)$ & $107(74)$ & $21(14)$ & 145 \\
Females & $3(2)$ & $95(70)$ & $38(28)$ & 136 \\
Total & $20(7)$ & $202(72)$ & $59(21)$ & 281 \\
\hline
\end{tabular}

Table 2.2 reveals the influence of gender on the level of assumption. The level of assumption is high for $28 \%$ of the female students than the total percentage (21\%). The assumption level for male students is $14 \%$ which is lower than the total percentage. Ho: Female students are high in assumption compared to male students. The computed value of $\chi^{2}$ (15.13) is more than the table value (5.99) at 5\% confidence level with 2 degrees of freedom. Hence the null hypothesis is rejected. It is thus concluded that there is no relationship between gender and assumption.

Table 2.3 Department and Assumption

\begin{tabular}{|lccccc|}
\hline Department & No. of responses & Average & Above average & Below average & Range \\
\hline Business & 78 & 3.02 & $21(27)$ & $57(73)$ & $1-4$ \\
Engineering & 170 & 2.68 & $105(62)$ & $65(38)$ & $0-4$ \\
Information Technology & 33 & 2.96 & $25(76)$ & $8(24)$ & $1-4$ \\
Total & 281 & 2.81 & $191(68)$ & $90(32)$ & $0-4$ \\
\hline
\end{tabular}

The relationship between department and assumption are shown in Table 2.3. The mean assumption for Business (3.02) and Information Technology (2.96) departments are higher than the total assumption mean (2.81). At the same time the mean assumption in Engineering department is 2.68 which is less than the average. The levels of assumption among the three departments are displayed in Table 2.4.

Table 2.4 Department and Assumption levels

\begin{tabular}{|lcccc|}
\hline Department & Lssumptions & Medium & High & Total \\
\hline Business & $2(2)$ & $55(71)$ & $21(27)$ & 78 \\
Engineering & $16(9)$ & $125(74)$ & $29(17)$ & 170 \\
Information Technology & $2(6)$ & $22(67)$ & $9(27)$ & 33 \\
Total & $20(7)$ & $202(72)$ & $59(21)$ & 281 \\
\hline
\end{tabular}

Table 2.4 exhibits $27 \%$ of students in Information Technology department and Business department have high assumption level than the total average (21\%). The assumption level for $67 \%$ of the students in the Engineering department is medium. Ho: Students of Business and Information Technology department have high assumption level. The observed value of $\chi^{2}(6.96)$ is less than the table value (9.49) at 5\% confidence level with 4 degrees of freedom. It is concluded that students from Business and Information Technology department have high assumption than Engineering department. 


\subsection{Deduction}

An exercise consisting of several statements followed by several suggested conclusions are given to the students. The statements in each exercise are considered as true without exception. The students should judge whether each conclusion follows the statement. The mean value of deduction is 1.88 . The standard deviation calculated is $0.79 .52 \%$ of the students have medium level of deduction. $21 \%$ of the students have high level of deduction ability in critical thinking.

Table 3.1 Gender and Deduction

\begin{tabular}{|llllll|}
\hline Gender & No. of responses & Average & Above average & Below average & Range \\
\hline Males & 145 & 1.85 & $108(74)$ & $37(36)$ & $0-3$ \\
Females & 136 & 1.91 & $97(71)$ & $39(29)$ & $0-3$ \\
Total & 281 & 1.88 & $205(73)$ & $76(27)$ & $0-3$ \\
\hline
\end{tabular}

The mean value of deduction for male students is 1.85 and that of females is 1.91 . The mean deduction for female students is more than the overall mean (1.88). Table 3.2 shows the relation between level of deduction and gender.

Table 3.2 Gender and levels of Deduction

\begin{tabular}{|lllll|}
\hline \multicolumn{1}{r}{ Gender } & Low & Medium & High & Total \\
\hline Males & & & & \\
Females & $37(25)$ & $78(54)$ & $30(21)$ & 145 \\
Total & $39(29)$ & $68(50)$ & $29(21)$ & 136 \\
& $76(27)$ & $146(52)$ & $59(21)$ & 281 \\
\hline
\end{tabular}

From table 3.2, male students and female students have high level of deduction which is equal to the overall percentage (21\%). Ho: Both male and female students are equally capable of deduction. The observed value of $\chi^{2}(0.24)$ is less than the table value (5.99) at 5\% confidence level with 2 degrees of freedom. Hence the null hypothesis is accepted. It is thus concluded that male and female students show equal level in deduction.

Table 3.3 Department and Deduction

\begin{tabular}{|llllll|}
\hline Department & No. of responses & Average & Above average & Below average & Range \\
\hline Business & 78 & 1.75 & $53(68)$ & $25(32)$ & $0-3$ \\
Engineering & 170 & 1.94 & $127(75)$ & $43(25)$ & $0-3$ \\
Information Technology & 33 & 1.88 & $25(76)$ & $8(24)$ & $0-3$ \\
Total & 281 & 1.88 & $205(73)$ & $76(27)$ & $0-3$ \\
\hline
\end{tabular}

The mean value of deduction for Engineering department is 1.94 which is more than the overall mean (1.88) whereas the mean score for Information Technology department is 1.88 which is same as the overall average. To analyse the relationship between the department and level of deduction, Table 3.4 is prepared.

Table 3.4 Department and level of Deduction

\begin{tabular}{|lllll|}
\hline \multicolumn{1}{r}{ Deduction } & Low & Medium & High & Total \\
\cline { 3 - 5 } Department & & & & \\
\hline Business & $25(32)$ & $44(56)$ & $9(12)$ & 78 \\
Engineering & $43(25)$ & $82(48)$ & $45(27)$ & 170 \\
Information Technology & $8(24)$ & $20(61)$ & $5(15)$ & 33 \\
Total & $76(27)$ & $146(52)$ & $59(21)$ & 281 \\
\hline
\end{tabular}

Table 3.4 exhibits that $27 \%$ of Engineering department students has high deduction level which is greater than total percentage (21\%). 56\% of students in Business department have medium level of deduction. Ho: Students of the Engineering department have a high deduction level. The observed value of $\chi^{2}(8.52)$ is in the acceptance region compared with the table value (9.49) at 5\% confidence level with 4 degrees of freedom. It is proved that Engineering department students have a high deduction level than other departments. 


\subsection{Interpretation}

The problem is to judge whether or not each of the proposed conclusions logically follows beyond a reasonable doubt from the information given. The mean value of interpretation is 1.44. The standard deviation calculated is 0.87 . Out of the 281 students, $74 \%$ have medium level of interpretation.

Table 4.1 Gender and Interpretation

\begin{tabular}{|llllll|}
\hline Gender & No of responses & Average & Above average & Below average & Range \\
\hline Males & 145 & 1.46 & $69(48)$ & $76(52)$ & $0-3$ \\
Females & 136 & 1.43 & $60(44)$ & $76(56)$ & $0-3$ \\
Total & 281 & 1.44 & $129(46)$ & $152(54)$ & $0-3$ \\
\hline
\end{tabular}

The mean score of interpretation for male students is 1.46 which is higher than the overall mean (1.44) and the mean score for female students is 1.43 . Table 4.1 shows that mean value of interpretation for male students is higher than the female students.

Table 4.2 Interpretation levels gender wise

\begin{tabular}{|lllll|}
\hline \multicolumn{1}{|c|}{ Interpretation } & Low & Medium & High & Total \\
Gender & & & & \\
\hline Males & $22(15)$ & $103(71)$ & $20(14)$ & 145 \\
Females & $16(12)$ & $105(77)$ & $15(11)$ & 136 \\
Total & $38(14)$ & $208(74)$ & $35(12)$ & 281 \\
\hline
\end{tabular}

From table 4.2, it is revealed that male students exhibit high level of interpretation (14\%) which is more than overall percentage (12\%). Ho: Male students have a high level of interpretation. The observed value of $\chi^{2}(1.39)$ is less than the table value (5.99) at 5\% confidence level with 2 degrees of freedom. Hence the null hypothesis is accepted. It is thus concluded that male students have high level of interpretation than females.

Table 4.3 Department and Interpretation

\begin{tabular}{|llllll|}
\hline Department & No. of responses & Average & Above average & Below average & Range \\
\hline Business & 78 & 1.37 & $32(41)$ & $46(59)$ & $0-3$ \\
Engineering & 170 & 1.44 & $80(47)$ & $90(53)$ & $0-3$ \\
Information Technology & 33 & 1.63 & $17(52)$ & $16(48)$ & $0-3$ \\
Total & 281 & 1.44 & $129(46)$ & $152(54)$ & $0-3$ \\
\hline
\end{tabular}

The mean value of interpretation for Information Technology students is 1.63 compared to the overall mean (1.44) whereas the mean score for Engineering department is 1.44 is same as the overall mean. Table 4.4 is prepared to determine the relationship between the department and level of interpretation.

Table 4.4 Department and level of Interpretation

\begin{tabular}{|lllll|}
\hline \multicolumn{1}{|c|}{ Interpretation } & Low & Medium & High & Total \\
Department & & & & \\
\hline Business & $11(14)$ & $59(76)$ & $8(10)$ & 78 \\
Engineering & $25(15)$ & $124(73)$ & $21(12)$ & 170 \\
Information Technology & $2(6)$ & $25(76)$ & $6(18)$ & 33 \\
Total & $38(14)$ & $208(74)$ & $35(12)$ & 281 \\
\hline
\end{tabular}

Table 4.4 displays $18 \%$ of students in Information Technology department are high in interpretation compared to the total percentage (12\%). The interpretation level for $76 \%$ of the students in Business and Information Technology department is medium. Ho: Students from Information Technology department have high interpretation level than other departments. The observed value of $\chi^{2}(2.79)$ is less compared to the table value (9.49) at $5 \%$ confidence level with 4 degrees of freedom. It is inferred that students of Information Technology department are high in interpretation. 


\subsection{Evaluation of Arguments}

In making decisions about important questions, it is desirable to distinguish between arguments that are strong and arguments that are weak. For an argument to be strong, it must be important and directly related to the question. An argument is weak if it is not directly related to the question. The mean value of argument is 1.53 . The standard deviation calculated is 0.79 . Out of the 281 students, $81 \%$ have medium level of argument.

Table 5.1 Gender and Argument skills

\begin{tabular}{|llllll|}
\hline Gender & No. of responses & Average & Above average & Below average & Range \\
\hline Males & 145 & 1.49 & $71(49)$ & $74(51)$ & $0-3$ \\
Females & 136 & 1.58 & $68(50)$ & $68(50)$ & $0-3$ \\
Total & 281 & 1.53 & $139(49)$ & $142(51)$ & $0-3$ \\
\hline
\end{tabular}

The mean value of argument for male students is 1.49 compared to the overall mean (1.53) and that of females is 1.58 compared to the total average.

Table 5.2 Gender and level of Argument skills

\begin{tabular}{|lllll|}
\hline \multicolumn{1}{|c}{ Gender } & Low & Medium & High & Total \\
\hline Males & $12(8)$ & $120(83)$ & $13(9)$ & 145 \\
Females & $9(6)$ & $107(79)$ & $20(15)$ & 136 \\
Total & $21(7)$ & $227(81)$ & $33(12)$ & 281 \\
\hline
\end{tabular}

Table 5.2 shows whether there is any difference in level of arguments and gender. $15 \%$ of the female students have high level of argument which is greater than the overall percentage (12\%). The high level of argument for male student is $9 \%$ which is less than the overall percentage. Ho: Female students have a high level of argument than male students. The observed value of $\chi^{2}$ (2.37) is less than the table value (5.99) at 5\% confidence level with 2 degrees of freedom. It is proved that female students show more argument skills in critical thinking than male students.

Table 5.3 Department and Argument skills

\begin{tabular}{|llllll|}
\hline Department & No. of responses & Average & Above average & Below average & Range \\
\hline Business & 78 & 1.60 & $41(53)$ & $37(47)$ & $0-3$ \\
Engineering & 170 & 1.50 & $83(49)$ & $87(51)$ & $0-3$ \\
Information Technology & 33 & 1.54 & $15(45)$ & $18(55)$ & $0-3$ \\
Total & 281 & 1.53 & $139(49)$ & $142(51)$ & $0-3$ \\
\hline
\end{tabular}

The mean value of argument for students from Information Technology department and Engineering departments are 1.54 and 1.50 respectively compared to overall mean (1.53) whereas the mean value for Business department is 1.60 as compared to total average. To verify the relationship between the department and argument levels table 5.4 is prepared.

Table 5.4 Department and level of Argument skills

\begin{tabular}{|lllll|}
\hline \multicolumn{1}{r}{ Arguments } & Low & Medium & High & Total \\
\cline { 1 - 4 } Business & & & & \\
Engineering & $4(5)$ & $64(82)$ & $10(13)$ & 78 \\
Information Technology & 0 & $30(91)$ & $3(9)$ & 33 \\
Total & $21(7)$ & $227(81)$ & $33(12)$ & 281 \\
\hline
\end{tabular}

Table 5.4 displays that $13 \%$ of students in Business department are high in argument compared to the overall percentage (12\%). The argument level for $91 \%$ students in the Information Technology department is medium. Hence the following hypothesis is framed and tested. Ho: Students of the Business department are high in argument level. The 
observed value of $\chi^{2}(5.33)$ is less than the table value (9.49) at $5 \%$ confidence level with 4 degrees of freedom. It is proved that Business department students are high in arguments than other departments.

3.6 Comparison of levels of critical variables and coefficient of variation

Table 6.1 Levels of critical thinking variables

\begin{tabular}{|llll|}
\hline \multicolumn{1}{|c}{ Levels } & Low & Medium & High \\
\hline Variables & & & \\
Anferences & $104(37)$ & $105(38)$ & $72(25)$ \\
Deduction & $20(7)$ & $202(7)$ & $59(21)$ \\
Interpretation & $76(27)$ & $146(52)$ & $59(21)$ \\
Evaluation of arguments & $21(7)$ & $227(81)$ & $33(12)$ \\
\hline
\end{tabular}

Among the critical thinking variables $25 \%$ of the students in Nizwa College of Technology have high level of inference which is greater than the other critical thinking attributes. Only $12 \%$ of the students have high interpretation level and evaluation of arguments. $21 \%$ of the students have high level of recognizing assumptions and making deductions. Ho: There is a significant difference in the critical thinking variables. The observed value of $\chi^{2}$ (178) is in the rejection area when compared with the table value (15.50) at 5\% confidence level with 8 degrees of freedom. It is inferred that there is no difference among the critical thinking attributes.

\section{Coefficient of variation}

Table 6.2 Coefficient of variation

\begin{tabular}{|llll|}
\hline Critical thinking variables & Mean & Standard Deviation & CV \\
\hline Inferences & 0.91 & 0.83 & 91.20 \\
Recognition of Assumptions & 2.81 & 0.86 & 30.60 \\
Deduction & 1.88 & 0.79 & 42.02 \\
Interpretation & 1.44 & 0.87 & 60.41 \\
Evaluation of arguments & 1.53 & 0.79 & 51.63 \\
\hline
\end{tabular}

The mean and standard deviation of each critical thinking variable are analysed separately. From the study it is revealed that recognition of assumptions is the most consistent and reliable factor among the students, whereas inference is inconsistent and not a reliable critical thinking factor among the students of Nizwa College of Technology.

\section{Comparison of critical thinking variables among departments and gender}

Table 6.3 Critical thinking variables department wise

\begin{tabular}{|llll|}
\hline Critical thinking variables & Engineering & $\begin{array}{l}\text { Information } \\
\text { Technology }\end{array}$ & Business \\
\hline Inferences & 0.96 & 0.88 & 0.79 \\
Recognition of Assumptions & 2.68 & 2.96 & 3.02 \\
Deduction & 1.94 & 1.88 & 1.75 \\
Interpretation & 1.44 & 1.63 & 1.37 \\
Evaluation of arguments & 1.50 & 1.54 & 1.60 \\
\hline
\end{tabular}

Table 6.3 reveals that Engineering students are better in inference (0.96) and deduction (1.94), Business students show well in recognition of assumptions (3.02) and evaluation of arguments (1.60). Interpretation mean is high for Information Technology students (1.63). To assess the relationship between the mean values of group attributes of 
critical thinking variables among department, Anova test is used. Ho: The means of the critical thinking attributes are unrelated with departments.

Table 6.4 Anova test result

\begin{tabular}{|lccccc|}
\hline Source & df & SS & MS & F & P-value \\
\hline Between & 2 & 0.018 & 0.0089 & 0.0160 & 0.9841 \\
Within & 12 & 6.65 & 0.5548 & & \\
Total & 14 & 6.67 & & & \\
\hline
\end{tabular}

The F-ratio is less than the P-value. The P value is greater than 0.05. It is concluded that the critical thinking variable averages of three departments are not related and they are independent. It is inferred that Engineering students are better in inference and deduction. Business students are better in recognition of assumptions and evaluation of arguments than other students. Information Technology students are better in Interpretation than other students.

Table 6.5 Critical thinking variables gender wise

\begin{tabular}{|lll|}
\hline Critical thinking variables & Males & Females \\
\hline Inferences & 0.97 & 0.83 \\
Recognition of Assumptions & 2.6 & 3.03 \\
Deduction & 1.85 & 1.91 \\
Interpretation & 1.46 & 1.43 \\
Evaluation of arguments & 1.49 & 1.58 \\
\hline
\end{tabular}

Table 6.5 shows that males have more critical thinking mean in inference and interpretation. The mean value of female students is high in recognition of assumptions, deduction and evaluation of arguments. Ho: The means of the critical thinking variables are unrelated with gender.

Table 6.6 Anova test result

\begin{tabular}{|lccccc|}
\hline Source & df & SS & MS & F & P-value \\
\hline Between & 1 & 0.017 & 0.0171 & 0.033 & 0.9874 \\
Within & 8 & 4.105 & 0.5132 & & \\
Total & 9 & 4.12 & & & \\
\hline
\end{tabular}

The F-ratio is less than the P-value. It is confirmed that the means of critical thinking variables are influenced by gender. The critical thinking variables of male and female students are proved to be independent.

\section{Findings of the study}

1. It is found that $25 \%$ of the students in Nizwa College of Technology have high inference level. $21 \%$ of the students have high level of assumption and deduction among the critical thinking variables. Only $12 \%$ of the students have high level of interpretation skills and evaluation of arguments.

2. The mean value of inference for male students is 0.97 and that for female students is 0.83 . The mean assumption for males is 2.6 and that of female students is 3.03. The mean score of deduction for male students is 1.85 and that of females is 1.91 . The mean value of interpretation for males students is 1.46 and females students is 1.43 . The mean score of argument for male students is 1.49 and that of females is 1.58. It is proved that male students excel in inference and interpretation than female students. It is proved that gender has no relationship on assumption and deduction. Females show more evaluation of argument level than male students. Hence female students from Business department are good in decision making than other students.

3. Students in Engineering department have a high inference level and high deduction level than other departments. Business and Information Technology department have a high assumption level than Engineering students. Students of Business department are high in evaluation of arguments than other departments. Students of Information Technology department are high in interpretation than other students. 


\section{Conclusion}

The advancement of knowledge largely depends on one's ability to think critically. Critical thinking skills enable a person to be successful in his profession. It is very crucial that students learn and acquire critical thinking skills during their higher education, as it creates a path to their career. This study gives a guideline how to improve on critical thinking by technical college students in Nizwa. The critical thinking variables that are analysed based on their gender and department wise provide significant results. These findings revealed that educational institutions should focus on developing the critical thinking ability of the students. Scholes (2012) present seven factors that can improve critical thinking in higher education students. The first one is explicit instruction in critical thinking (Marin \& Halpern, 2010, Abrami et al, 2008, Pithers \& Soden, 2000). This could be an exclusive critical thinking course, or mixed methods approach, or infusion approach (alerting students to what they are doing and how and why to do it). The second one is teacher feedback. This could be a written feedback on students' work, or a feedback on student questions. The third factor that helps to gain critical thinking skills in students is argument diagramming (Van Gelder, 2005; Brock and Wilson, 2010). This is when students do a visual breakdown of an argument, noting the premises and conclusion and considering objections. Students might either construct their own argument, or they could be provided with an argument and then construct their own argument diagram of it. The fourth factor is an assessment to ensure more practice and opportunities for feedback (e.g. Borg \& Stranahan, 2010; Brock and Wilson, 2010). It is the drafting, writing, re-drafting and re-writing process that is thought to be beneficial. Peer learning, involving students collaborating in learning, discussing and explaining their understanding and ideas, is suggested as a factor helpful for supporting critical thinking. Qualitative studies have reported this as a factor improving critical thinking (Tsui, 2008). Researchers have suggested that encouraging reflection on course content can increase critical thinking skills. It is reviewing and considering course concepts by one's own. Researchers recommend reducing amount of content in a course to leave more time for reflection. The last factor is diversity experiences, which involves interacting with people from diverse backgrounds.

\section{Recommendations}

1. Educational institutions should emphasize on developing the critical thinking ability skills early in higher education.

2. Students must be made aware of the relevance of critical thinking and how these skills can increase the employability when they graduate.

3. Critical thinking should be made as a part of curriculum in higher education wherein the students are given exercises on making inferences, deductions, interpretations, recognizing assumptions and evaluating arguments. Active reading should be encouraged amongst students in order to improve their inference skills.

4. Scientific concepts and application could be one of the reasons Engineering department showed high in inference and deduction level. Business and Information Technology department were considerably low in these variables. Hence they should focus on a practical oriented approach than a conceptual oriented approach in academics.

5. To enhance the critical thinking skills student centered activities should be given like presentation from the handout, supplementing examples, and class room exercises.

\section{References}

Abrami, Philip C.; Bernard, Robert M.; Borokhovski, Evgueni; Wade, Anne; Surkes, Michael A.; Tamim, Rana; Dai Zhang. (2008). Review of Educational Research. Dec2008, Vol. 78 Issue 4, p1102-1134. http://dx.doi.org/10.3102/0034654308326084

Bailin, S. (2002). Critical Thinking and Science Education. Science \& Education, 11(4), 361-375. http://dx.doi.org/10.1023/A:1016042608621

Borg, Mary O \& Stranahan, Harriet, A. (2010) Evidence on the relationship between economics and critical thinking skills. Contemporary Economic Policy, 28 (1): 80-93. http://dx.doi.org/10.1111/j.1465-7287.2008.00134.x

Brock, Stuart, Wilson, Marc \& R.A. Hudson Talent Management. Measuring critical thinking abilities. 2010 Learning and Teaching Grant Final Report. Last accessed 21 October 2013, from http://www.cad.vuw.ac.nz/resources/landtfund/2010/reports/Brock.pdf

Ennis, R. (2011). Robert H Ennis' Academic Web Site. http://faculty.education.illinois.edu/rhennis/, last accessed 21 October 2014. 
Giancarlo, C., \& Facione, P. (2001). A Look across Four Years at the Disposition toward Critical Thinking among Undergraduate Students. The Journal of General Education, 50(1), 29-55. http://dx.doi.org/10.1353/jge.2001.0004

Hager, P., \& Kaye, M. (1992). Critical Thinking in Teacher Education: A Process-Oriented Research Agenda. Australian Journal of Teacher Education, 17(2). http://dx.doi.org/10.14221/ajte.1992v17n2.4

Halpern, D. F. (1998). Teaching Critical Thinking for Transfer across Domains. Dispositions, Skills, Structure, Training, and Metacognitive Monitoring. The American Psychologist, 53(4), 449-455. http://dx.doi.org/10.1037/0003-066X.53.4.449

Kennedy, M., Fisher, M. B., \& Ennis, R. H. (1991). Critical thinking: Literature review and needed research. In L. Idol \& B.F. Jones (Eds.), Educational values and cognitive instruction: Implications for reform (pp. 11-40). Hillsdale, New Jersey: Lawrence Erlbaum \& Associates.

Lewis, A., \& Smith, D. (1993). Defining Higher Order Thinking. Theory into Practice, 32(3), 131-137. http://dx.doi.org/10.1080/00405849309543588

Marin, Lisa \& Halpern, Diane (2011). Pedagogy for developing critical thinking in adolescents: Explicit instruction produces greatest gains. Thinking Skills and creativity, 6 (1):1-13. http://dx.doi.org/10.1016/j.tsc.2010.08.002

Paul, R. W. (1992). Critical thinking: What, why, and how? New Directions for Community Colleges, 1992(77), 3-24. http://dx.doi.org/10.1002/cc.36819927703

Phrakhruvisitpattanaporn, Saner Piromjitrapong \& Saman Asavabhumi (2012), A Teaching Method to Develop a Critical Thinking of the Students of the General Education Ecclesiastical School, Journal of Social Sciences, 8 (3), 467-471. http://dx.doi.org/10.3844/jssp.2012.467.471

Pithers, R.T \& Soden, Rebecca (2000). Critical thinking in education: a review, Educational Research, 42:3, 237-249. http://dx.doi.org/10.1080/001318800440579

Robert H. Ennis. (1993) Critical Thinking Assessment, Theory and Practice, Teaching for Higher Order Thinking, Volume 32, Number 3, College of Education, The Ohio State University.

Scholes, V. (2012). Improving critical thinking in tertiary students. Presented at the 2012 Conference of the Australasian Association of Philosophy (NZ Division), Victoria University of Wellington, Pipitea Campus, 2-6 December 2012.

Stella Cottrell, Critical Thinking Skills Developing Effective Analysis and Argument, Palgrave Macmillan, Second Edition, 2011.

Sternberg, R. J. (1986). Critical Thinking: Its Nature, Measurement, and Improvement National Institute of Education. Retrieved from http://eric.ed.gov/PDFS/ED272882.pdf.

Tsui, Lisa (2008) Cultivating critical thinking: insights from an elite liberal arts college. The Journal of General Education, 56 (3-4): 200-227. http://dx.doi.org/10.1353/jge.0.0001

Van Gelder, T (2005). Teaching Critical Thinking: Some Lessons from Cognitive Science. College Teaching, 53(1), 41-48. http://doi:10.3200/CTCH.53.1

Willingham, D.T. (2007). Critical thinking: Why is it so hard to teach? American Educator, 8-19. 